\title{
Enhanced electrical resistivity and mechanical properties in BCTZ-based composite ceramic*
}

\author{
Xiaodong Yan, Mupeng Zheng ${ }^{\dagger}$, Mankang Zhu and Yudong Hou \\ Key Laboratory of Advanced Functional Materials \\ Education Ministry of China College of Materials Science and Engineering \\ Beijing University of Technology Beijing 100124, P. R. China \\ $\dagger^{\dagger}$ mpzheng@bjut.edu.cn
}

Received 21 August 2019; Revised 15 September 2019; Accepted 19 September 2019; Published 18 October 2019

\begin{abstract}
Environmental and human health concerns about lead toxicity have prompted the development of lead-free piezoceramics. Among them, $\left(\mathrm{Ba}_{0.85} \mathrm{Ca}_{0.15}\right)\left(\mathrm{Zr}_{0.1} \mathrm{Ti}_{0.9}\right) \mathrm{O}_{3}$ (BCTZ) with excellent piezoelectric properties has the most potential and attracts extensive attention. However, lack of concern toward electrical resistivity and mechanical properties has greatly hindered its practical application. Here, we report the achievement of enhanced insulation characteristics (grain electrical resistivity increased by one order of magnitude) and superior mechanical properties (Vickers hardness value increased by $40 \%$ ) in $\mathrm{Al}_{2} \mathrm{O}_{3}$-added $\mathrm{BCTZ}$ composite ceramics. Such improvement can be attributed to specific composite microstructure, where the nonferroelectric second phase dispersed in the grain interior and grain boundary of BCTZ matrix results in blocking effect on the electric current paths as well as propagation of microcracks. These findings will pave a new way for the practical application of BCTZ ceramics.
\end{abstract}

Keywords: Lead-free; perovskite; composite ceramic; electrical resistivity; mechanical properties.

\section{Introduction}

Piezoelectric materials as a class of functional materials can respond to applied mechanical stress and vice-versa, and are widely used in actuator, sensor and energy harvesting devices. ${ }^{1-3}$ Due to the excellent piezoelectric properties, leadbased perovskite ferroelectrics are the most popularly used piezoelectric materials. ${ }^{4}$ However, they are currently facing global restrictions due to their $\mathrm{Pb}$ toxicity, thus, a lead-free alternative that can compete with lead-based ones is urgently needed to be designed and studied. Among the family of lead-free piezoelectric materials, ${ }^{5} \mathrm{BaTiO}_{3}$-based perovskite has stood out since its solid solution $(1-x) \mathrm{Ba}\left(\mathrm{Zr}_{0.2} \mathrm{Ti}_{0.8}\right) \mathrm{O}_{3-} x$ $\left(\mathrm{Ba}_{0.7} \mathrm{Ca}_{0.3}\right) \mathrm{TiO}_{3}$ (abbreviated as $\mathrm{BCTZ}$ ) was reported to possess surprisingly high piezoelectric properties (e.g., $d_{33} \sim$ $620 \mathrm{pC} / \mathrm{N}$ ) due to the composition proximity of the morphotropic phase boundary (MPB) to the tricritical triple point, which leads to a nearly vanishing polarization anisotropy and thus facilitates polarization rotation. ${ }^{5}$ This discovery has stimulated intensive research on the lead-free piezoelectric ceramics, especially for $(\mathrm{Ba}, \mathrm{Ca})(\mathrm{Ti}, \mathrm{Zr}) \mathrm{O}_{3}$ systems. Keeble et al. ${ }^{6}$ constructed revised structural phase diagram of BCTZ system and confirmed the implication of the orthorhombic phase in reconciling the exceptional piezoelectric properties. Ehmke and $\mathrm{Li}$ et al. ${ }^{7,8}$ studied the effect of poling processing on the performance of the BCTZ ceramics. Tao et al. ${ }^{9}$ investigated the dielectric relaxation behavior and impedance spectroscopic of BCTZ ceramics. Meanwhile, enhanced piezoelectric properties have also been achieved via some methods such as chemical doping or optimization of the experimental process (powder synthesis, sintering control and poling condition). ${ }^{10-13}$ But there are two important items which are generally neglected. One is the electrical resistivity as a ceramic needs to be fully polarized at high enough field, and the leakage current should be as low as possible for device operation. ${ }^{7,14}$ To the best of our knowledge, there are rare reports focused toward enhancing electrical resistivity of $(\mathrm{Ba}, \mathrm{Ca})(\mathrm{Ti}, \mathrm{Zr}) \mathrm{O}_{3}$ ceramics. In general, doping can greatly affect the electrical resistivity of materials. ${ }^{14,15}$ The donor impurities can induce $A$-site vacancies, contribute electrons to the conduction process and compensate $O$-site vacancy in the $p$-type electrical conduction compounds, such as PZTs, and increase their resistivity. ${ }^{16}$ Zhou et al. ${ }^{14}$ found that $\mathrm{W}^{6+}$ donor dopant decreased the conductivity in $\mathrm{Bi}_{3} \mathrm{TiNbO}_{9}$ piezoceramics by as much as two orders of magnitude. In addition, a composite design strategy that introduces high insulation second phase into matrix phase is also considered as an effective approach. ${ }^{17-19}$ Recently, Zhao and Wu investigated effects of secondary phases on the permittivity in $\mathrm{TiO}_{2}$ ceramics, and found that the increased grain boundary resistance can be contributed to the optimized permittivity and low dielectric loss with appropriate contents of secondary phases. ${ }^{19}$ Zhou et al. ${ }^{18}$ found that the resistivity of $\mathrm{Na}_{0.5} \mathrm{Bi}_{2.5} \mathrm{Nb}_{2} \mathrm{O}_{9}$ piezoceramics increased about two orders of

\footnotetext{
*This paper was originally submitted to the special issue on lead-free piezo/ferroelectric materials.
}

This is an Open Access article published by World Scientific Publishing Company. It is distributed under the terms of the Creative Commons Attribution 4.0 (CC BY) License which permits use, distribution and reproduction in any medium, provided the original work is properly cited. 
magnitude by adding highly insulating $\mathrm{Al}_{2} \mathrm{O}_{3}$, leading to the higher electric field being applied during poling process.

Another aspect are the mechanical properties, which are essential for improving the working stability of devices, especially for piezoelectric vibration energy harvester, ${ }^{20}$ where the piezoelectric materials experience large number of mechanical cycles and, in some situations, shock stresses. Currently, a few results toward enhancing mechanical properties of BCTZ ceramics were reported, ${ }^{21,22}$ and constructing composite ceramics reinforced with the second phase have been proved to be an effective means. ${ }^{23}$ However, there is a lack of substantial discussions on the physical mechanism of mechanical performance improvement.

In this work, we are committed to improving the resistivity and mechanical properties of BCTZ ceramics. The classical $\left(\mathrm{Ba}_{0.85} \mathrm{Ca}_{0.15}\right)\left(\mathrm{Zr}_{0.1} \mathrm{Ti}_{0.9}\right) \mathrm{O}_{3}$ with superior piezoelectric properties was selected as starting composition, which was widely investigated for high-performance leadfree piezoelectric devices. However, as two major factors affecting performance in practical applications, its resistivity and mechanical properties have not been intensively studied. Here, we achieved both high electrical resistivity and good mechanical properties in BCTZ ceramics by introducing highly insulated $\mathrm{Al}_{2} \mathrm{O}_{3}$ into $\mathrm{BCTZ}$ ceramic matrix. As a major contributor, the formation sequence and ingredient of secondary phase were systematically studied.

\section{Experimental}

Lead-free BCTZ powders were synthesized by a conventional solid-state reaction technique. The calcining was performed at $1200^{\circ} \mathrm{C}$, and then the BCTZ powders were milled for $12 \mathrm{~h}$. After drying, required amounts of $\mathrm{Al}_{2} \mathrm{O}_{3}(x=0-6$ vol.\%) were added to the calcined BCTZ powders and ball milled again for $12 \mathrm{~h}$. Two-step sintering process was conducted to obtain dense ceramic, rate-controlled sintering was programmed at a heating rate of $300^{\circ} \mathrm{C} / \mathrm{h}$. After maintaining at $1500^{\circ} \mathrm{C}$ for $5 \mathrm{~min}$, the temperature was rapidly decreased to $1350^{\circ} \mathrm{C}$, then held for $4 \mathrm{~h}$. The morphology and composition of polished samples were analyzed by field-emission scanning electron microscopy (SEM-BSE; FEI, Quanta 650, USA) equipped with an energy-dispersive X-ray spectroscopy (EDS). Vickers indentation hardness of the materials was determined via a digital microhardness tester (HXD1000TMC/LCD, Taiming Inc., Shanghai, China). AC impedance analysis were measured using a broadband impedance spectrometer (Novocontrol Technologies, Montabaur, Germany). Samples for piezoelectric measurements were poled in a silicone oil bath at $40^{\circ} \mathrm{C}$ under a DC field of $40 \mathrm{kV} / \mathrm{cm}$ for $30 \mathrm{~min}$. Other detailed preparation process and measurement methods have been described elsewhere. ${ }^{24}$

\section{Results and Discussion}

Figures 1(a)-1(c) show the AC impedance spectroscopic measured at every $20^{\circ} \mathrm{C}$ interval in a temperature range of $220-300^{\circ} \mathrm{C}$ for $\mathrm{Al}_{2} \mathrm{O}_{3}$ added $\mathrm{BCTZ}$ ceramics. In the order of decreasing frequency, two arcs are corresponding to the responses of the grain and the grain boundaries, respectively. ${ }^{25}$ To investigate the variation of the electrical properties of grain and grain boundary with increasing $\mathrm{Al}_{2} \mathrm{O}_{3}$ content,

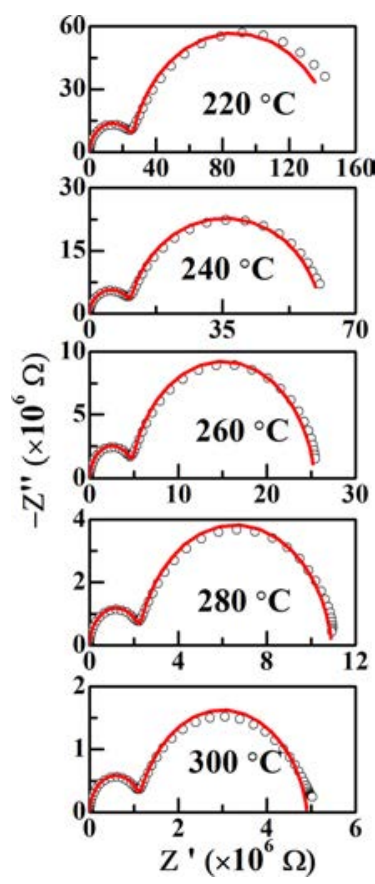

(a)

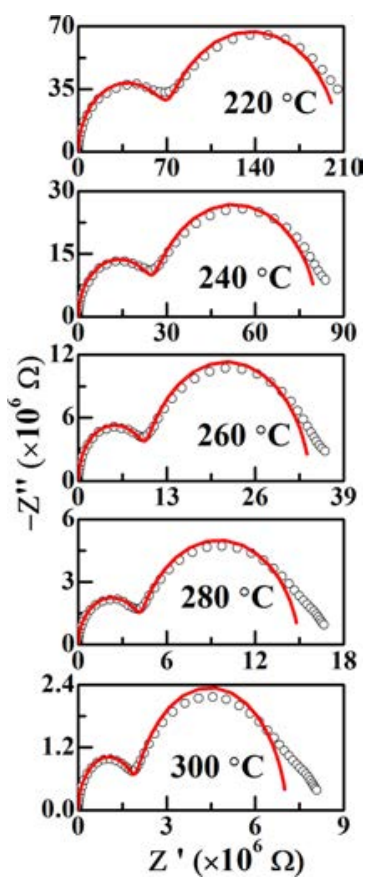

(b)

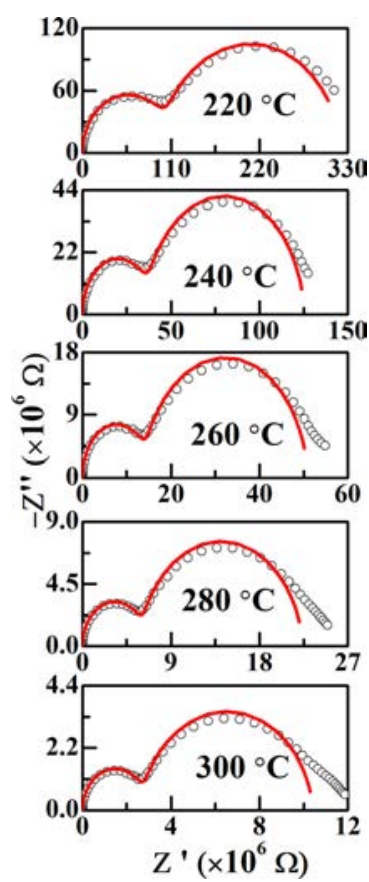

(c)

Fig. 1. Complex impedance plots of BCTZ ceramics with different $\mathrm{Al}_{2} \mathrm{O}_{3}$ additions: (a) $x=0$, (b) $x=2$ and (c) $x=6$. 
an impedance spectroscopy fitting was applied, and the simulated results (red line) are also shown in Fig. 1. Two distinct $R Q$ responses with smaller error can easily be observed in all temperature ranges for the pure BCTZ specimen. In contrast, arcs corresponding to the low frequency responses present a larger deviation for $x=2$ and $x=6$ specimens, which are attribute to more complex grain boundary structure due to the introduction of secondary phase. To further investigate effect of secondary phase on insulating properties and defect structure of grain and grain boundary, their conductivities $\sigma_{g}, \sigma_{g b}$ were calculated, respectively by the following formula: ${ }^{26}$

$$
\begin{gathered}
\sigma_{g}=\frac{t}{R_{g} \cdot A}, \\
\sigma_{g b}=\frac{t \cdot C_{g}}{R_{g b} \cdot A \cdot C_{g b}},
\end{gathered}
$$

where $t$ is thickness of sample and $A$ is area. $R_{g}, C_{g}, R_{g b}$ and $C_{g b}$ represents resistance and capacitance of grain and grain boundary, respectively. The temperature dependence of $\sigma_{g}$ and $\sigma_{g b}$ are presented in Fig. 2, the specific grain boundary conductivity was roughly four-orders of magnitude lower than the grain one. With the $\mathrm{Al}_{2} \mathrm{O}_{3}$ addition, grain conductivity shows a significant drop (about one order of magnitude), indicating existence of highly insulating phase in BCTZ ceramic matrix. ${ }^{14}$ Furthermore, we can detect the

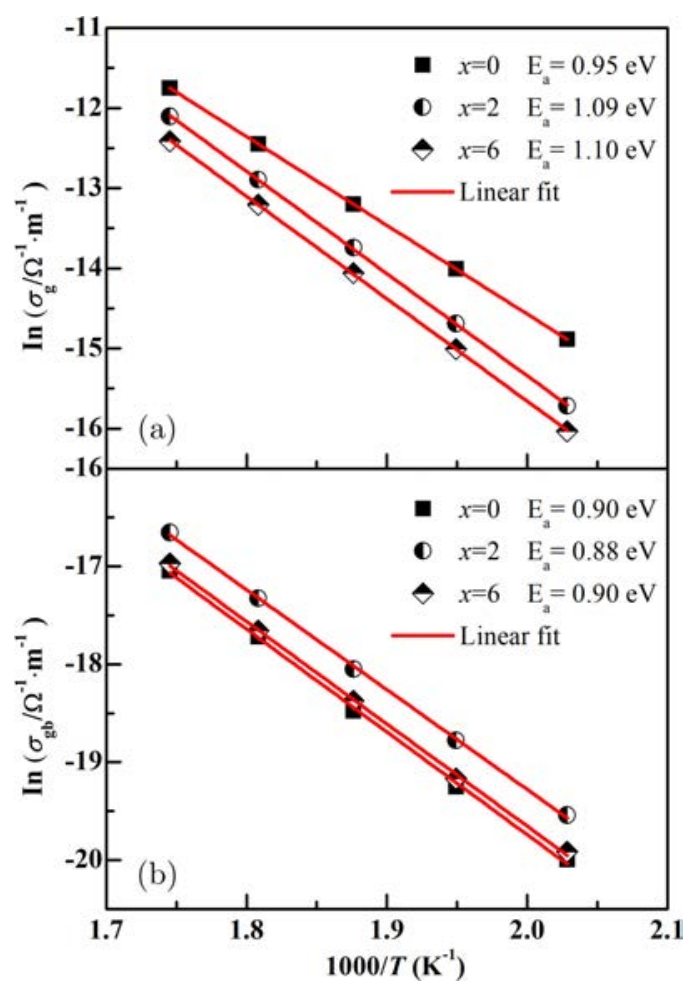

Fig. 2. Arrhenius plots of the temperature-dependent (a) bulk and (b) grain boundary conductivities of the $\mathrm{Al}_{2} \mathrm{O}_{3}$ added $\mathrm{BCTZ}$ ceramic, and the fitted activation energy $\left(E_{\mathrm{a}}\right)$ values are obtained. activation energies $\left(E_{\mathrm{a}}\right)$ of the grain and grain boundary for electrical conductivity by using the Arrhenius equation: ${ }^{27}$

$$
\sigma=\sigma_{0} \exp \left(-\frac{E_{a}}{k_{\mathrm{B}} T}\right),
$$

where $\sigma_{0}$ is the pre-exponential factor, $E_{a}$ is the activation energy, $k_{B}$ is the Boltzmann constant, and $T$ is the absolute temperature. Figure 2 shows the plot of $\ln \sigma_{g}, \ln \sigma_{g b}$ versus $1 / T$, in which the solid line is fitted by Eq. (3). As can be seen, the activation energies for grain increases from $0.95 \mathrm{eV}$ for $x=0$ to $1.09 \mathrm{eV}$ for $x=2$, then to $1.10 \mathrm{eV}$ for $x=6$, which indicates reduced concentration of defect such as oxygen vacancies. ${ }^{9}$ As a comparison, the activation energy for grain boundary has no obvious variation with introduction of $\mathrm{Al}_{2} \mathrm{O}_{3}$.

To uncover the origin of the evolution of conductivity as well as activation energy, microstructure analysis of specimens was conducted. Figure 3(a) gives XRD patterns of $\mathrm{Al}_{2} \mathrm{O}_{3}$ added $\mathrm{BCTZ}$ ceramics, and it is evident that all the samples are dominated by perovskite structure, whereas some additional peaks for $\mathrm{Al}_{2} \mathrm{O}_{3}$ added specimens appear by magnified patterns for $2 \theta$ regions around $28-29^{\circ}, 34-35^{\circ}$, as shown in Figs. 3(b) and 3(c), surprisingly, these peaks do not belong to $\mathrm{Al}_{2} \mathrm{O}_{3}$ phase. When $x=1$, only single additional peak can be observed at $2 \theta$ near $28.8^{\circ}$, which can not correspond well with anyone of JCPDF. With further increase of $\mathrm{Al}_{2} \mathrm{O}_{3}$ content, peaks at $2 \theta$ near $28.3^{\circ}$ and $34.4^{\circ}$ emerge and gradually increase in intensity, which is consistent with diffraction lines of $\mathrm{BaAl}_{2} \mathrm{O}_{4}(\mathrm{JCPDF} \# 17-0306)$. For further characterizing the phase evolution, the temperature-dependent dielectric constant and loss curves are presented in Fig. 3(d). When $x=0$, three anomalies can be clearly observed, indicating three phase transition, which correspond to rhombohedral-orthorhombic $(R-O)$ phase transition temperature $T_{R-O}$, orthorhombic-tetragonal $(O-T)$ phase transition temperature $T_{O_{-} T}$ and tetragonal-cubic $(T-C)$ phase transition temperature $T_{m}$, from low temperature to high temperature. ${ }^{6}$ With the addition of $\mathrm{Al}_{2} \mathrm{O}_{3}$, these phase transitions become gradually diffuse, and Curie peaks present a drastically decreasing trend, which may be related to effect of nonferroelectric second phase. ${ }^{28}$

To confirm the presence of $\mathrm{BaAl}_{2} \mathrm{O}_{4}$ and identify the ingredient of incipient secondary phase, backscattered electron SEM image of polished section for $\mathrm{Al}_{2} \mathrm{O}_{3}$ added ceramics and EDS analysis of different contrast regions is implemented and shown on Fig. 4. For pure BCTZ ceramic, EDS result confirm that the composition is initial BCTZ, as shown on Fig. 4(a). More importantly, some secondary phase (gray region) are dispersed in the grain boundary for $x=1$ sample, shown on Fig. 4(b), EDS result indicates that incipient secondary phase is a compound consisted of $\mathrm{Ba}, \mathrm{Ca}, \mathrm{Ti}$, $\mathrm{Zr}, \mathrm{Al}$ and $\mathrm{O}$, followed by formation of $\mathrm{BaAl}_{2} \mathrm{O}_{4}$ at matrix with $x=2$, shown on Fig. 4(c), which could be attributed to the chemical reactions between $\mathrm{BCTZ}$ and $\mathrm{Al}_{2} \mathrm{O}_{3}$ occurring during high temperature sintering process. ${ }^{22}$ With further 

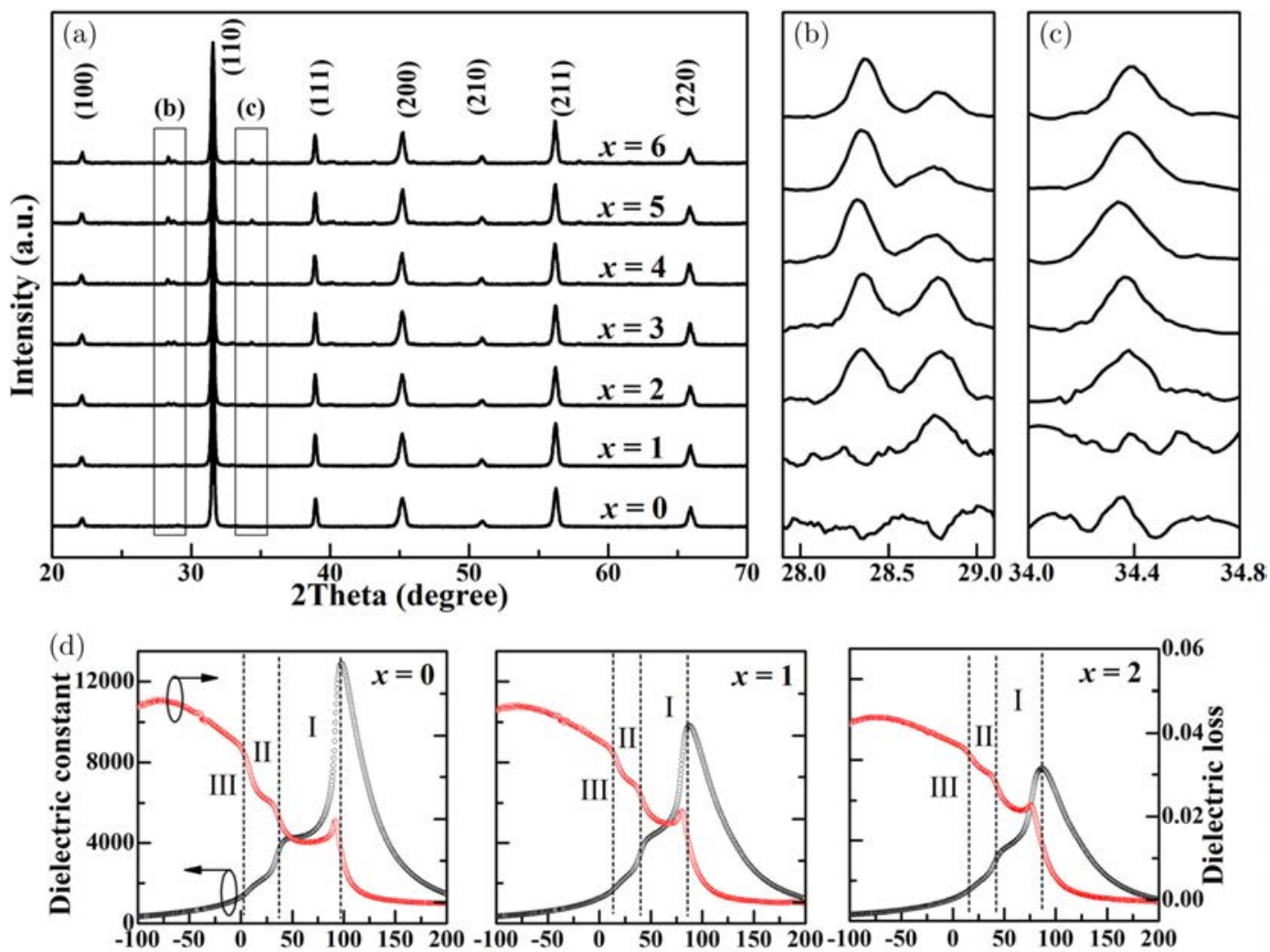

Temperature $\left({ }^{\circ} \mathrm{C}\right)$
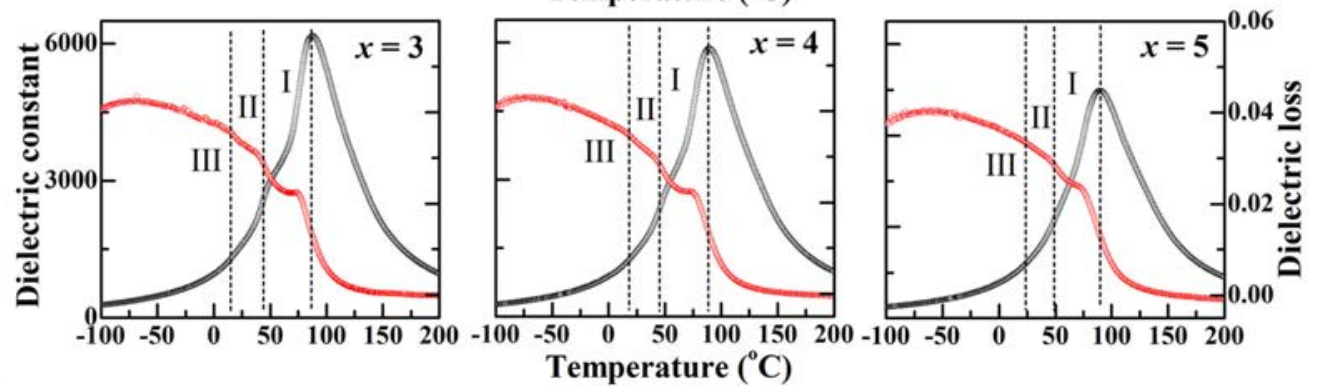

Fig. 3. (a) XRD patterns, enlargement of (b) $28^{\circ} \sim 29^{\circ}$, (c) $34^{\circ} \sim 35^{\circ}$ and (d) temperature dependent dielectric constant and loss curves for the $\mathrm{Al}_{2} \mathrm{O}_{3}$ added $\mathrm{BCTZ}$ ceramics.

increase $x$, content of second phase simultaneously increase and distributed in not only grain boundary triangle but also grain inside (see Fig. 4(d)). As a result, addition of $\mathrm{Al}_{2} \mathrm{O}_{3}$ result in formation of different secondary phase depend on amount of $\mathrm{Al}_{2} \mathrm{O}_{3}$ in $\mathrm{BCTZ}$ ceramic, small amount of $\mathrm{Al}_{2} \mathrm{O}_{3}$ can induce a new compound. However, higher amount of $\mathrm{Al}_{2} \mathrm{O}_{3}$ addition $(>1$ vol.\%) resulted in nonferroelectric secondary phase $\mathrm{BaAl}_{2} \mathrm{O}_{4}$. These highly insulating secondary phases locating at the grain boundaries and the smaller spherical grains being formed by $\mathrm{Al}_{2} \mathrm{O}_{3}$ addition, can reduce or even avoid pores at triangle, which can result in significant blocking effect on the electric current paths and hence enhanced electrical resistivity. ${ }^{18}$

Figure 5(a) shows the polarization-electric field $(P-E)$ hysteresis loops of the $\mathrm{Al}_{2} \mathrm{O}_{3}$ added $\mathrm{BCTZ}$ composite ceramics. The pure BCTZ ceramic presents typical hysteresis loop with low coercive field $E_{c}$ and a relatively high remnant polarization $\left(P_{r}\right)$. However, the $P_{r}$ and maximum polarization $\left(P_{\max }\right)$ decreased with increasing $\mathrm{Al}_{2} \mathrm{O}_{3}$ content, which can be attributed to the formation of nonferroelectric $\mathrm{BaAl}_{2} \mathrm{O}_{4}$ phase. $^{22,28}$ Piezoelectric coefficient $\left(d_{33}\right)$ and electromechanical coupling coefficient $\left(k_{p}\right)$ of BCTZ composite ceramics are shown in Fig. 5(b). It is observed that the $d_{33}$ and $k_{p}$ values also gradually decrease with increasing $\mathrm{Al}_{2} \mathrm{O}_{3}$ content. ${ }^{28}$

Generally, the microstructure of ceramics not only has an important influence on the electrical properties, but also will determine their mechanical properties. To evaluate the mechanical performance of $\mathrm{Al}_{2} \mathrm{O}_{3}$ added $\mathrm{BCTZ}$ ceramics, the indentation test was carried out. Figure 6(a) presents a representative SEM image of Vickers indentation for $1 \mathrm{vol} \%$ $\mathrm{Al}_{2} \mathrm{O}_{3}$ added BCTZ ceramic. The Vickers indentation hardness $H_{\mathrm{v}}$ values were measured using a load of $1.96 \mathrm{~N}$ for $10 \mathrm{~s}$, 


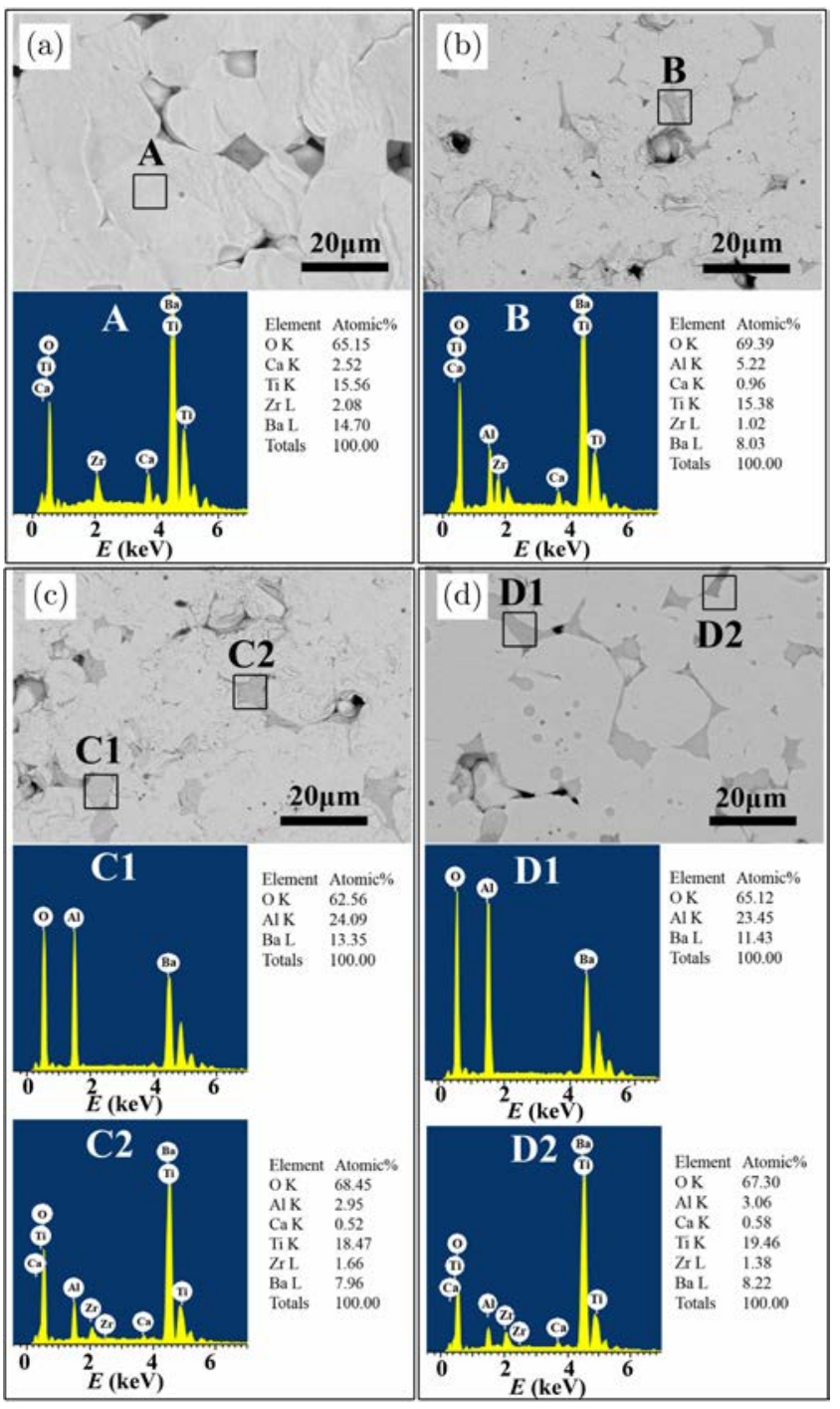

Fig. 4. Backscattered electron SEM images and EDS analysis of matrix grain and the secondary phase of composite ceramics (dark color refer to the secondary phases) with different $\mathrm{Al}_{2} \mathrm{O}_{3}$ additions: (a) $x=0$, (b) $x=1$, (c) $x=2$ and (d) $x=6$.

and the corresponding fracture toughness $K_{\mathrm{IC}}$ was calculated using the following equation: ${ }^{29}$

$$
K_{\mathrm{IC}}=\frac{0.0624 P}{d l^{0.5}}
$$

where $P$ is the load, $d$ is the diagonal length of the indentation, $l$ is the crack's vertical length measured from the tip of indentation, as marked in Fig. 6(a). Figure 6(b) gives the composition dependent $H_{\mathrm{v}}$ and $K_{\mathrm{IC}}$ values. For pure BCTZ sample, $H_{\mathrm{v}}$ and $K_{\mathrm{IC}}$ is about $4.35 \mathrm{GPa}$ and $0.91 \mathrm{MPa} \cdot \mathrm{m}^{1 / 2}$, respectively. With the addition of $\mathrm{Al}_{2} \mathrm{O}_{3}$, both $K_{\mathrm{IC}}$ and $H_{\mathrm{v}}$ value gradually increase, which are significantly higher than unadded counterpart. Classically, high $H_{\mathrm{v}}$ and $K_{\mathrm{IC}}$ values are considered to be related to the effect of increased grain boundaries, resulted from decreasing grain sizes (see Fig. S1, Supplementary Materials), which is consistent with the

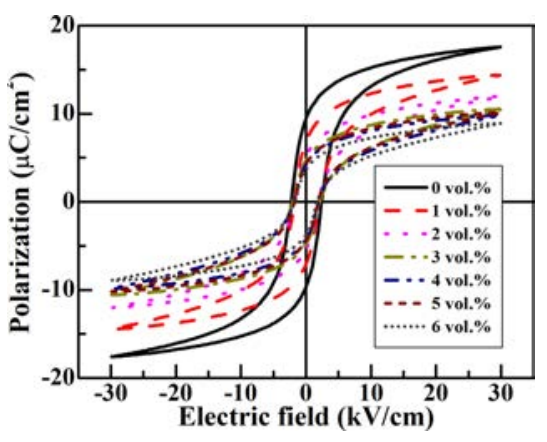

(a)

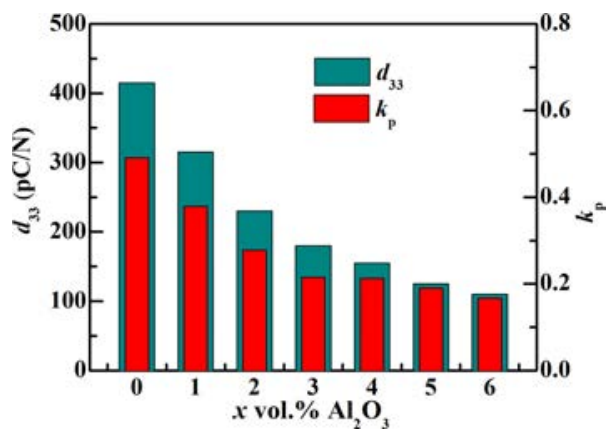

(b)

Fig. 5. (a) Polarization-electric field $(P-E)$ hysteresis loops and (b) $d_{33}$ and $k_{\mathrm{p}}$ of the $\mathrm{Al}_{2} \mathrm{O}_{3}$ added $\mathrm{BCTZ}$ ceramics.

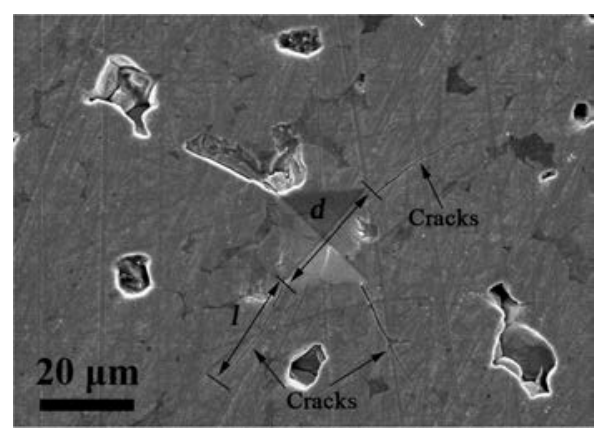

(a)

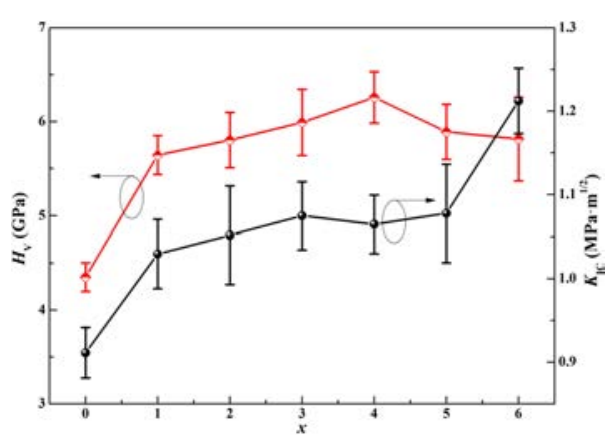

(b)

Fig. 6. (a) SEM image of Vickers indentation for the 1 vol. $\% \mathrm{Al}_{2} \mathrm{O}_{3}$ added BCTZ ceramic and (b) the Vickers hardness and fracture toughness values of the samples with different $\mathrm{Al}_{2} \mathrm{O}_{3}$ content. 
previous reports. ${ }^{30,31}$ In addition, secondary phase particles precipitated into BCTZ matrix, leading to undulating grainboundary structure, which can provide additional obstacles for the movement of lattice dislocations and propagation of microcracks in the adjacent grains, may be partly contributing to the increasing $K_{\mathrm{IC}}{ }^{21}$ For sample with $x=4, H_{\mathrm{v}}$ and $K_{\mathrm{IC}}$ reach about $6.26 \mathrm{GPa}$ (increased by $\sim 40 \%$ compared with initial value) and $1.06 \mathrm{MPa} \cdot \mathrm{m}^{1 / 2}$, respectively. The $H_{\mathrm{v}}$ value achieved here is higher than that of most piezoelectric ceramics (usually below 5.00 GPa) and even comparable with fine-grained PZT-based ceramics, ${ }^{20,21,29,30}$ indicating that $\mathrm{Al}_{2} \mathrm{O}_{3}$ added $\mathrm{BCTZ}$ ceramics are potential in high quality piezoelectric application.

\section{Conclusions}

Enhanced electrical resistivity and superior mechanical properties were reported in $\mathrm{BCTZ}$ composite ceramics by the introduction of highly insulating $\mathrm{Al}_{2} \mathrm{O}_{3}$. The results indicate that $\mathrm{Al}_{2} \mathrm{O}_{3}$ induced two kinds of secondary phase, including Al-rich BCTZ compounds and $\mathrm{BaAl}_{2} \mathrm{O}_{4}$ phases. These secondary phase distributed in not only grain boundary but also grain inside, leading to significant effect on mechanical properties and electrical properties of BCTZ ceramics. We believe that properly modified BCTZ composite ceramic with the comprehensive performance were promising candidates for lead-free piezoelectric applications.

\section{Acknowledgments}

This work was supported by National Natural Science Foundation of China (Grant Nos. 51677001 and 51602012), Beijing Natural Science Foundation (Grant No. 2192009), the Fundamental Research Funds for the Beijing Municipal Universities (PXM2019-014204-500031, PXM2019-014204-500032).

\section{References}

${ }^{1}$ G. H. Haertling, Ferroelectric ceramics: History and technology, J. Am. Ceram. Soc. 82, 797 (1999).

${ }^{2}$ J. Rodel, W. Jo, K. T. P. Seifert, E. M. Anton, T. Granzow and D. Damjanovic, Perspective on the development of lead-free piezoceramics, J. Am. Ceram. Soc. 92, 1153 (2009).

${ }^{3}$ C. R. Bowen, H. A. Kim, P. M. Weaver and S. Dunn, Piezoelectric and ferroelectric materials and structures for energy harvesting applications, Energy Environ. Sci. 7, 25 (2014).

${ }^{4}$ J. Rödel, K. G. Webber, R. Dittmer, W. Jo, M. Kimura and D. Damjanovic, Transferring lead-free piezoelectric ceramics into application, J. Eur. Ceram. Soc. 35, 1659 (2015).

${ }^{5}$ W. F. Liu and X. B. Ren, Large piezoelectric effect in $\mathrm{Pb}$-free ceramics, Phys. Rev. Lett. 103, 257602 (2009).

${ }^{6}$ D. Keeble, F. Benabdallah, P. Thomas, M. Maglione and J. Kreisel, Revised structural phase diagram of $\left(\mathrm{Ba}_{0.7} \mathrm{Ca}_{0.3} \mathrm{TiO}_{3}\right)$ $\left(\mathrm{BaZr}_{0.2} \mathrm{Ti}_{0.8} \mathrm{O}_{3}\right)$, Appl. Phys. Lett. 102, 092903 (2013).

${ }^{7}$ M. C. Ehmke, J. Glaum, M. Hoffman, J. E. Blendell, K. J. Bowman and J. Roedel, The effect of electric poling on the performance of lead-free $(1-x) \mathrm{Ba}\left(\mathrm{Zr}_{0.2} \mathrm{Ti}_{0.8}\right) \mathrm{O}_{3}-x\left(\mathrm{Ba}_{0.7} \mathrm{Ca}_{0.3}\right) \mathrm{TiO}_{3}$ piezoceramics, J. Am. Ceram. Soc. 96, 3805 (2013).

${ }^{8}$ B. Li, M. C. Ehmke, J. E. Blendell and K. J. Bowman, Optimizing electrical poling for tetragonal, lead-free BZT-BCT piezoceramic alloys, J. Eur. Ceram. Soc. 33, 3037 (2013).

9J. Tao, Z. Yi, Y. Liu, M. Zhang, J. Zhai and X. Tan, Dielectric tunability, dielectric relaxation, and impedance spectroscopic studies on $\left(\mathrm{Ba}_{0.85} \mathrm{Ca}_{0.15}\right)\left(\mathrm{Ti}_{0.90} \mathrm{Zr}_{0.10}\right) \mathrm{O}_{3}$ lead-free ceramics, J. Am. Ceram. Soc. 96, 1847 (2013).

${ }^{10}$ E. Chandrakala, J. P. Praveen, A. Kumar, A. R. James and D. Das, Strain-induced structural phase transition and its effect on piezoelectric properties of (BZT-BCT)- $\left(\mathrm{CeO}_{2}\right)$ ceramics, J. Am. Ceram. Soc. 99, 3659 (2016).

${ }^{11}$ J. P. Praveen, T. Karthik, A. R. James, E. Chandrakala, S. Asthana and D. Das, Effect of poling process on piezoelectric properties of sol-gel derived BZT-BCT ceramics, J. Eur. Ceram. Soc. 35, 1785 (2015).

${ }^{12} \mathrm{P}$. Wang, Y. Li and Y. Lu, Enhanced piezoelectric properties of $\left(\mathrm{Ba}_{0.85} \mathrm{Ca}_{0.15}\right)\left(\mathrm{Ti}_{0.9} \mathrm{Zr}_{0.1}\right) \mathrm{O}_{3}$ lead-free ceramics by optimizing calcination and sintering temperature, J. Eur. Ceram. Soc. 31, 2005 (2011).

${ }^{13}$ S. Su, R. Zuo, S. Lu, Z. Xu, X. Wang and L. Li, Poling dependence and stability of piezoelectric properties of $\mathrm{Ba}\left(\mathrm{Zr}_{0.2} \mathrm{Ti}_{0.8}\right) \mathrm{O}_{3^{-}}$ $\left(\mathrm{Ba}_{0.7} \mathrm{Ca}_{0.3}\right) \mathrm{TiO}_{3}$ ceramics with huge piezoelectric coefficients, Curr. Appl. Phys. 11, S120 (2011).

${ }^{14}$ Z. Zhou, X. Dong, H. Chen and H. Yan, Structural and electrical properties of $\mathrm{W}^{6+}$-Doped $\mathrm{Bi}_{3} \mathrm{TiNbO}_{9}$ high-temperature piezoceramics, J. Am. Ceram. Soc. 89, 1756 (2006).

${ }^{15}$ B. Guiffard, E. Boucher, L. Eyraud, L. Lebrun, D. Guyomar, Influence of donor co-doping by niobium or fluorine on the conductivity of Mn doped and $\mathrm{Mg}$ doped PZT ceramics, J. Eur. Ceram. Soc. 25, 2487 (2005).

${ }^{16} \mathrm{~L}$. Wu, T. S. Wu, C. C. Wei and H. C. Liu, The DC resistivity of modified PZT ceramics, J. Phys. C: Solid State Phys. 16, 2823 (1983)

${ }^{17}$ Z. Shen, X. Wang, H. Gong, L. Wu and L. Li, Fabrication of high-performance $\mathrm{Ba}_{0.95} \mathrm{Ca}_{0.05} \mathrm{Ti}_{0.85} \mathrm{Zr}_{0.15} \mathrm{O}_{3}$ ceramics by aqueous chemical coating method, Ceram. Int. 41, S157 (2015).

${ }^{18}$ Z. Zhou, R. Liang, Y. Li, X. Dong and D. C. Lupascu, Enhanced electrical resistivity of $\mathrm{Al}_{2} \mathrm{O}_{3}$ addition modified $\mathrm{Na}_{0.5} \mathrm{Bi}_{2.5} \mathrm{Nb}_{2} \mathrm{O}_{9}$ high-temperature piezoceramics, J. Am. Ceram. Soc. 98, 3925 (2015).

${ }^{19} \mathrm{C}$. Zhao and J. Wu, Effects of secondary phases on the highperformance colossal permittivity in titanium dioxide ceramics, ACS Appl. Mater. Interfaces 10, 3680 (2018).

${ }^{20}$ M. P. Zheng, Y. D. Hou, X. D. Yan, L. N. Zhang and M. K. Zhu, A highly dense structure boosts energy harvesting and cycling reliabilities of a high-performance lead-free energy harvester, J. Mater. Chem. C 5, 7862 (2017).

${ }^{21} \mathrm{P}$. Adhikari, R. Mazumder and S. Abhinay, Electrical and mechanical properties of $\mathrm{MgO}$ added $0.5 \mathrm{Ba}\left(\mathrm{Zr}_{0.2} \mathrm{Ti}_{0.8}\right) \mathrm{O}_{3}-0.5$ $\left(\mathrm{Ba}_{0.7} \mathrm{Ca}_{0.3}\right) \mathrm{TiO}_{3}(\mathrm{BZT}-0.5 \mathrm{BCT})$ composite ceramics, J. Electroceram. 37, 127 (2016).

${ }^{22}$ P. Adhikari, R. Mazumder and G. K. Sahoo, Electrical and mechanical properties of $0.5 \mathrm{Ba}\left(\mathrm{Zr}_{0.2} \mathrm{Ti}_{0.8}\right) \mathrm{O}_{3}-0.5\left(\mathrm{Ba}_{0.7} \mathrm{Ca}_{0.3}\right) \mathrm{TiO}_{3}$ (BZT-BCT) lead free ferroelectric ceramics reinforced with nanosized $\mathrm{Al}_{2} \mathrm{O}_{3}$, Ferroelectrics 490, 60 (2016).

${ }^{23} \mathrm{~S}$. Jiansirisomboon and A. Watcharapasorn, Effects of alumina nano-particulates addition on mechanical and electrical properties of barium titanate ceramics, Curr. Appl. Phys. 8, 48 (2008). 
${ }^{24}$ X. D. Yan, M. P. Zheng, Y. D. Hou and M. K. Zhu, Compositiondriven phase boundary and its energy harvesting performance of BCZT lead-free piezoelectric ceramic, J. Eur. Ceram. Soc. 37, 2583 (2017).

${ }^{25} \mathrm{X}$. Guo and Z. Zhang, Grain size dependent grain boundary defect structure: Case of doped zirconia, Acta Mater. 51, 2539 (2003).

${ }^{26} \mathrm{X}$. Guo and Y. Ding, Grain boundary space charge effect in zirconia, J. Electrochem. Soc. 151, J1 (2004).

${ }^{27}$ I. Coondoo, N. Panwar, R. Vidyasagar and A. L. Kholkin, Defect chemistry and relaxation processes: Effect of an amphoteric substituent in lead-free BCZT ceramics, Phys. Chem. Chem. Phys. 18, 31184 (2016).

${ }^{28}$ X. Yu, Y. Hou, M. Zheng, H. Zhao and M. Zhu, A composite approach boosts transduction coefficients of piezoceramics for energy harvesting, AIP Adv. 8, 035018 (2018).
${ }^{29}$ M.-P. Zheng, Y.-D. Hou, H.-Y. Ge, M.-K. Zhu and H. Yan, Effect of $\mathrm{NiO}$ additive on microstructure, mechanical behavior and electrical properties of $0.2 \mathrm{PZN}-0.8 \mathrm{PZT}$ ceramics, J. Eur. Ceram. Soc. 33, 1447 (2013).

${ }^{30}$ M. Zheng, Y. Hou, M. Zhu, M. Zhang and H. Yan, Shift of morphotropic phase boundary in high-performance fine-grained PZN-PZT ceramics, J. Eur. Ceram. Soc. 34, 2275 (2014).

${ }^{31}$ X. Chao, Z. M. Wang, Y. Tian, Y. Zhou and Z. Yang, Ba $\left(\mathrm{Cu}_{0.5} \mathrm{~W}_{0.5}\right) \mathrm{O}_{3}$-induced sinterability, electrical and mechanical properties of $\left(\mathrm{Ba}_{0.85} \mathrm{Ca}_{0.15}\right)\left(\mathrm{Ti}_{0.90} \mathrm{Zr}_{0.10}\right) \mathrm{O}_{3}$ ceramics sintered at low temperature, Mater. Res. Bull. 66, 16 (2015). 